\title{
O gênero excepcional: apontamentos sobre a recepção de narrativas de escravos nos EUA
}

\author{
Felipe Vale da Silva ${ }^{1}$
}

\begin{abstract}
Resumo: $\mathrm{O}$ artigo trata de uma história dupla de resistência: primeiramente, das narrativas de escravos como instrumento de luta contra o sistema escravagista dos EUA e, por outro lado, da resistência oferecida pelo establishment literário posterior, que negou lugar ao gênero no cânone. Analisaremos três argumentos acerca da recepção desse primeiro momento da prosa afro-americana no século XX. Tal exercício nos permite constatar como muitos de seus elementos estruturais foram compreendidos progressivamente, conforme abordagens interdisciplinares se acumularam e formaram uma comunidade de leitores apta a apreciá-las como um gênero singular daquele país. Para cada argumento desfavorável à apreciação das narrativas de escravos, será contrastado um exemplo literário excepcional: em primeiro lugar isolaremos os tratamentos literários do New Criticism ao de F. O. Matthiessen com uma análise da retórica da obra de Frederick Douglass; em um segundo momento, o argumento de John Sekora contra a forma híbrida das narrativas de escravos será contrastado com a perspectiva estruturalista de Olney; nesse momento, contrastaremos as narrativas de Venture Smith, James Williams e William Grimes.
\end{abstract}

Palavras-chave: Narrativas de escravos. Literatura afro-americana. Frederick Douglass. História de recepção. Abolicionismo.

Palavras -quão inocentes e inofensivas são quando se encontram no dicionário, e quão poderosas para fazer bem e mal se tornam nas mãos daquele que sabe combiná-las. $^{2}$

Nathaniel Hawthorne, American Notebooks, 1848

Narrativas de escravos são comumente associadas ao movimento abolicionista dos EUA em sua fase mais militante, de 1831 em diante. Como poucas manifestações literárias modernas, esses textos foram compostos de forma programática: associações antiescravistas coordenadas angariavam fundos, abordavam escravos fugidos de suas comunidades e publicavam relatos de suas vidas. O tema destes era claro: "a realidade da escravidão e a

\footnotetext{
${ }^{1}$ Doutor em Letras (Literatura Alemã) pela Universidade de São Paulo. No momento atua como pesquisador de pós-doutorado junto à Universidade Federal de Goiás. Bolsista CAPES. GO, Brasil. E-mail:

felipe.vale.silva@gmx.com (10) https://orcid.org/0000-0002-2146-6550

${ }^{2}$ No original: "Words - so innocent and powerless as they are, as standing in a dictionary, [and] how potent for [doing] good and evil they become, in the hands of one who knows how to combine them". Doravante, todas as traducões serão de autoria do articulista.
} 
necessidade de aboli-la". ${ }^{3}$ Quando os ex-escravizados não soubessem escrever, logo se encontraria algum amanuense disposto a representá-los, tal qual um advogado de defesa perante a corte da opinião pública.

O consórcio entre ativistas brancos e fugitivos negros teve uma importância sem igual nas letras estadunidenses, e issopor mais de uma razão.Ele permitiu a criação de um espaço cultural onde, como nunca dantes, a experiência afro-americana se fizesse conhecerna grande mídia,e, dessa forma, os abusos do sistema escravocrata fossem denunciados numa nova chave. Ademais, o próprio abolicionismo, quase exclusivamente composto por ianques brancos até a década de 1820, passou a contar com contribuições de intelectuais negros do Sul. Dali em diante, ele se transformou em um movimento de dimensões nacionais, mais radical e efetivo, que continha em si uma variedade cultural e linguística inexistente em demais vanguardas culturais da época.

Embora existam relatos biográficos de negros escravizados antes de 1831, eles derivam de um contexto de escrita muito diverso. Para citarmos dois exemplos, obras de autores como Olaudah Equiano (de 1789) e Robert Adams (de 1816) descrevem a passagem transatlântica do ponto de vista de marujos africanos. Apesar de serem biografias de excativos - homens que viram suas famílias sendo vendidas e sofreram crueldades por parte de mestres abusivos -, elas se configuram como um misto de romances de aventuras e confissões religiosas, tão ao gosto do século XVIII (GOULD, 2007, p. 13-16). Não há em seu cerne um objetivo declarado de contar uma história de libertação, de forma a expor tanto o caráter criminoso da escravidão quanto os disparates do racismo. Antes, o cativeiro figura nesses textos como um dentre vários problemas pessoais do protagonista, do qual se livra por sorte ou esforço próprio.

Interessados no tema da escravidão, sobretudo no continente americano, encaram tais textos com certa resistência. Embora valiosos como fonte de conhecimento etnográfico sobre o antigo Mundo Atlântico, ora eles resvalam em descrições de um passado africano bucólico, ora reproduzem servilmente astópicas do romance britânico de Defoe e Swift. Eles são, em grande medida, frutos da fantasia, e seus autores parecem não ser "um de nós", como pontua Reid-Pharr (2007, p. 138). Tais relatos dizem menos respeito do Novo Mundo e suas instituições do que os de autores posteriores, que nasceram e negociaram a abolição da

\footnotetext{
3 "[t] he theme is the reality of slavery and the necessity of abolishing it [...]" (OLNEY, 1984, p. 53).
} 
escravatura por aqui. Diferentemente de narrativas pós-1845, eles fracassam em confrontarnos com cenários e práticas discursivas advindos de um ponto crucial de nossa história coletiva, situado nas vésperas da libertação de afrodescendentes nas Américas. Isso ocorre, nas palavras de Charles Nichols Jr., pois, ao lê-los, observamos "menos evidências de manipulação abolicionista, um tom menos sentimental e propagandístico e, em geral, uma edição e impressão menos cuidadosa". ${ }^{4}$

Não nos enganemos aqui: ao falarmos de manipulação, devemos pensá-la no contexto político em que narrativas de escravos fugidos emergiram. Os propósitos imediatos daqueles textos determinaram seu formato; "escritos para servir à causa abolicionista, [eles] rapidamente desenvolveram um conjunto de convenções retoricamente efetivas de grande ressonância política". ${ }^{5}$ Contra a natureza utilitária desses textos surgiram duas grandes objeções por parte da crítica. Estas, argumentaremos aqui, foram as grandes responsáveis pela presença fugaz desses textos na educação universitária, no mercado literário e mesmo nos grandes compêndios de história da literatura estadunidense. A isso soma-se fato de que, uma vez que a Guerra da Secessão terminou com a abolição da escravatura, esses textos foram "dispensados como, no máximo, curiosidades irrelevantes e ultrapassadas". 6

Nos tópicos seguintes analisaremos as principais objeções no século $\mathrm{XX}$ contra o gênero narrativas de escravos. Seja por meio de argumentos estéticos ou ideológicos, todas essas objeções se provaram insuficientemente rigorosas, porém, incapazes de negar à literatura afro-americana o direito ao cânone. A partir dos anos 1970 ela volta à voga, quando surge uma comunidade de críticos e público capazes de entendê-las em seus próprios termos. Ao compreendermos o histórico de críticas às narrativas de escravos, será possível ampliarmos o espectro de dimensões nelas contidas. Tais críticas contribuíram para pensarmos o gênero em modalidades diversas, mostrando que, longe de ser meros repositórios de dados sociológicos sobre a escravidão, ele se constituiu como a grande novidade para as belas letras estadunidenses do século XIX.

\footnotetext{
4 “[...] fewer evidences of abolitionist tampering, a less sentimental and propagandistic tone and, in general, a less careful editing and printing” (NICHOLS Jr., 1951, p. 553).

5 "Written to serve the abolitionist cause, the narratives quickly developed a set of rhetorically effective conventions with great political resonance [...]” (BRUCE Jr., 2007, p. 28).

6 "[they] were dismissed as, at best, irrelevant and outdated curiosities" (SEKORA, 1987, p. 482).
} 


\section{Primeira crítica - a tese do alheamento (do New Criticism a Matthiessen) e o caso Frederick Douglass}

Esta objeção parte de um fato indiscutível: a primeira prosa afro-americana se alheou do resto do cânone anglo-saxão. Sua impropriedade, portanto, foi a de funcionar às margens das grandes tendências e do desenvolvimento orgânico da cultura intelectual estadunidense. Tanto o New Criticism quanto críticos com pendores neorromânticos da metade do século XX desqualificaram a produção afro-americana inicial como 'menos original' e 'esteticamente inferior' à grande arte em língua inglesa que lhe foi contemporânea, de Coleridge a Emerson. Esse argumentar com base em predileções pessoais, por mais deficiente que seja, reflete-se no modo que a primeira prosa dos negros e negras figura até hoje os grandes compêndios de literatura daquele país. Via de regra, grandes autores como Frederick Douglass, William Wells Brown e Harriet Ann Jacobs aparecem na condição de curiosidades, de fenômenos estranhos ao espírito de seu tempo. ${ }^{7}$

O caso do New Criticism é fácil de entender: aquele foi o movimento cuja premissa é o exato oposto da de qualquer grupo de ativistas políticos. A arte deveria ser descontextualizada de toda política, biografia e contexto social, e o texto ser analisado como um artefato autocontido. Autores inclinados a ideias da artpourl'art ganharam prominência imediata; aqueles que, como ex-escravos, escreviam com objetivos políticos explícitos, foram sumariamente ignorados.

Já o caso de um crítico como F. O. Matthiessen é menos óbvio. Como pensador de extração hegeliana, Matthiessen isolou a reação literária imediatamente posterior à época tão pouco democrática de 1829 a 1849 - isto é, que liga o início do mandato de Andrew Jackson ao fim do governo James Polk - , declarando-a o lustro da Renascença Americana. O nome de sua obra-prima era American Renaissance: Art and Expression in the Age of Emerson and Whitman (1949 [1941]). A seu ver, os tais cinco anos poderiam ser resumidos a cinco grandes obras, publicadas por cinco grandes autores:

- Ralph Waldo Emerson, Representative Men (1850);

- Nathaniel Hawthorne, The Scarlet Letter (1850);

- Henry David Thoreau, Walden; or, Life in the Woods (1854);

- Walt Whitman, Leaves of Grass (1855);

\footnotetext{
${ }^{7}$ Acerca da desconfiança acadêmica perante a primeira literatura afro-americana, ver o ensaio de Toni Morrison (1989, p. 9 et seq). 
- Hermann Melville, Moby-Dick; or, The Whale (1851).

O denominador comum entre esses homens da Nova Inglaterra, de históricos tão diferentes, era sua "devoção às possibilidades da democracia". ${ }^{8}$ A década precedente a essa, os anos 1840, continua Matthiessen, foi palco para mais movimentos de reforma do que qualquer década na história - o que é uma afirmação razoável. Aquela foi a época da Primavera dos Povos na Europa, de tentativas revolucionárias em dezenas de países do mundo, de descontentamento generalizado com o colonialismo e efeitos colaterais da Revolução Industrial.

$\mathrm{O}$ erro de Matthiessen foi entender bem aquela época de radicalização, mas elencar subjetivistas moderados para representá-la; Thoreau e Whitman talvez fizessem parte de uma vanguarda progressista louvada por Matthiessen, mas certamente não era o caso dos outros. Curiosamente, na mesma época foram lançados textos abolicionistas menos propícios a defender "a infinitude do homem privado" (1949, p. 6) e mais interessados na mobilização das massas para a criação de um novo país, com uma nova legislação; menos guiados por uma “aceitação mística de que a intuição tinha a palavra final” (1949, p. 9), como no caso dos transcendentalistas, e mais propensos a argumentar a causa da abolição por meio de argumentos jurídicos, teológicos e filosóficos. Seguem alguns exemplos ignorados na obra em questão:

- William Wells Brown, Clotel; or, the President Daughter (1853);

- Solomon Northup, Twelve years a slave (1853);

- Harriet Beecher Stowe, Uncle Tom's Cabin; or, Life Among the Lowly(1852);

- Frederick Douglass, What is to the Slave the Fourth of July? (1852) e My Bondage and Freedom (1855).

De qualquer perspectiva que os vejamos, tais textos tiveram maior impacto imediato que qualquer um elencado por Matthiessen. Se obras transcendentalistas geraram uma revolução na intelectualidade da Nova Inglaterra, estas contribuíram para a abolição da escravatura. Sua influência sobre outros autores foi maior, assim como suas vendas: o livro de Stowe, afinal, foi a obra literária mais vendida e traduzida no século XIX, vendendo 300.000 exemplares nos EUA em seu primeiro ano de circulação, mais 1.000 .000 de cópias da

\footnotetext{
8 “[...] their devotion to the possibilities of democracy" (MATTHIESSEN, 1949, p. ix). 
Inglaterra durante o mesmo período.A primeira narrativa de Douglass vendeu 5.000 cópias em quatro meses, 11.000 cópias nos primeiros dois anos. ${ }^{9}$

Por fim, Matthiessen termina por trair sua própria metodologia. Num extenso capítulo sobre Emerson, ele elenca o tom declamatório, improvisado, afim à oratória, como a característica distintiva da nova literatura estadunidense (1949, p.22-23). A prosa americana por excelência distingue-se da britânica por ser multimodal; ela contém em si

filosofia, ética, teologia, crítica, poesia, humor, diversão, arremedos, anedotas, piadas, ventriloquismo, toda a extensão e versatilidade das conversas mais liberais; os tópicos mais e menos elevados, pessoais e locais; tudo é permitido, e tudo pode ser combinado em um discurso. ${ }^{10}$

Essa é uma melhor descrição de um romance de um William Wells Brown do que da ensaística de Emerson. Em outras palavras, também nesse ponto, Matthiessen acerta o diagnóstico sobre o que há de tão inovador na literatura estadunidense, mas esquece de reconhecer os escritores negros da época como grandes propulsores de novidades.

Há de se considerar dois fatores adicionais aqui quando pensamos na obsessão de Matthiessen por inovação, um dos conceitos-guia de seu estudo. Se seus autores românticos e transcendentalistas, melhor atrelados ao tal 'espírito da época', estavam em busca de uma arte apartada dos discursos do dia a dia, a vanguarda abolicionista tinha uma guerra institucional a vencer por meio da escrita. De uma perspectiva da história global das ideias, autores abolicionistas foram os primeiros americanos a compor textos ficcionais de cariz ativista, mais próximos ao espírito da nova arte europeia daquela época (como a da Junges Deutschland de Heinrich Heine e Ludwig Börne) do que foi a arte dos próprios transcendentalistas. ${ }^{11}$

O argumento da originalidade é curiosamente perverso, portanto. Quando Matthiessen localiza a grande renascença das letras americanas na obra de Emerson, Hawthorne e Melville, ele cai numa contradição desastrosa: todos esses escritores foram importadores

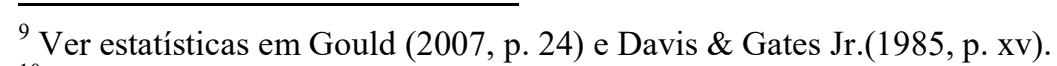

10 "[...] philosophy, ethics, divinity, criticism, poetry, humor, fun, mimicry, anecdotes, jokes, ventriloquism, all the breadth and versatility of the most liberal conversation; highest, lowest, personal, local topics, all are permitted, and all may be combined in one speech [...]" (MATTHIESSEN, 1949, p. 23).

${ }^{11}$ Para seus detratores, o Transcendentalismo americano sempre foi censurado como um subproduto do idealismo alemão, como um arremedo da sentenciosidade do velho Goethe ou de um ou outro romântico já falecido. Para um histórico detalhado da literatura europeia no contexto de lutas sociais dos anos 1830 e 1840, ver Silva, 2017.
} 
declarados de estéticas europeias já antigas na época. Enquanto isso, escravos fugidos escreviam e publicavam livros repletos de folclore em dialetos sulistas, tratando de tensões contemporâneas da América. A rigor, a originalidade — estética e tematicamente falando estava ao lado deles. De fato, já no momento de sua concepção, esta foi reconhecida como a primeira tradição literária exclusivamente estadunidense. Já em 1864, Theodor Parker reconheceu:

Possuímos um grupo de produções literárias que não podem ser escritas senão por americanos, e apenas aqui [nos EUA]; refiro-me às Vidas de Escravos Fugidos. Todo o [universo] romanesco original dos americanos jaz neles, e não no romance do homem branco. ${ }^{12}$

Sendo uma literatura estranha aos valores estéticos do Romantismo, nossa obrigação como historiadores literários é a de entendê-la em seus próprios termos. Nela, o documental se sobrepõe ao fantasiado; seu estilo é econômico, explícito, sem floreios. Os fatos pesam mais que os pensamentos contidos, sendo descritos cronologicamente, muitas vezes sem levar em conta impressões das personagens envolvidas na ação. O que há a se contar, sobretudo, é muito diverso dos devaneios de escritores românticos: para um cativo a única coisa que importa são os passos necessários para sua fuga.

A última afirmação pode soar contrafatual. Trechos reflexivos são abundantes na obra do grande representante da vertente Frederick Douglass, um mestre em arroubos líricos bastante próximos à retórica do Romantismo. Segue o exemplo do trecho muito citado da Narrativa da vida de Frederick Douglass, um escravo americano, capítulo X:

Vocês [naus na Baía de Chesapeake] estão soltas dos atracadouros, e são livres. Eu tenho as correntes apertadas em torno de mim, e sou um escravo! Vocês se movem alegremente ao vento, e eu pesaroso diante do chicote! Vocês são os anjos de asas ligeiras da liberdade, que correm pelo mundo, enquanto eu estou confinado com elos de ferro! Ah, se eu fosse livre! Ah, se eu estivesse em um de seus conveses imponentes, e sob a proteção de suas asas! Mas - ai de mim! Entre nós, correm as águas revoltas. Vão, vão embora. Quem me dera ir também! (DOUGLASS, 2018, p. 71)

\footnotetext{
12 “[...] we have one series of literary productions that could be written by none but Americans, and only here; I mean the Lives of Fugitive Slaves. [...] all the original romance of Americans is in them, not in the white man's novel" (PARKER, 1864, p. 245). Tal convicção não é uma ideia isolada de Parker e sua era; ela volta ser veiculada num texto recente como o de Charles Johnson (1999, p. xii).
} 
No contexto, o jovem Douglass interrompe o trabalho para observar os navios à margem da Baía de Chesapeake, em Maryland. Reconhecemos aquele recurso originalmente dramático, o qual os românticos resgataram de Shakespeare, do solilóquio, a pausa dramática em que um protagonista faz um balanço de sua experiência discursando perante objetos inanimados. No caso, Douglass escolheu o símbolo da libertação do homem provinciano, o navio, para retratar o estranho paradoxo que surgia em sua mente imatura: barcos podem se jogar pelos mares, enquanto o garoto negro está atracado à terra. A partir daí, conta o autor, a alma daquela criança se torna inquieta.

No entanto, uma reflexão como esta servem ao presente da iniciação, ao momento em que o ex-cativo, já gozando de liberdade, conscientiza o público leitor acerca da realidade da escravidão, aqui em sua dimensão existencial. É bastante improvável que um adolescente cativo, desconhecedor do alfabeto e dos livros, tenha recorrido a um solilóquio altamente estilizado, contendo preposições arcaicas (no original ele utiliza betwitxt em vez de between) ou orações subjuntivas (como $O$ that I were free, considerada uma formulação do inglês culto; ver DOUGLASS, 1845, p. 64). Certamente o jovem Douglass não proferiu aquelas palavras, e isso pouco importa para os fins de seu texto. O que importa é a expressão da ânsia por liberdade como uma característica essencialmente humana, radicalmente necessária mesmo para quem sempre se encontra em grilhões e na ignorância.

Abolicionista atento que era, Douglass mostra plena consciência de que a primeira luta a ser travada contra o sistema escravista era de ordem ideológica."Treinados do berço para acharem e sentirem que seus mestres eram superiores, e revestidos de um tipo de sacralidade, havia poucos que conseguiam erguer-se sobre o controle que o sentimento exercia", ele problematiza em sua terceira narrativa. ${ }^{13} \mathrm{~A}$ construção da cena em que o jovem anseia sua liberdade como que por instinto, pela primeira vez, tem uma papel importante no desmonte de uma ideia fixa do século XIX.Mesmo algumas pseudociências da época (como a frenologia) operavam na direção de uma naturalização da escravidão - segundo esse discurso, a ordem natural criara a hierarquia entre raças humanas. Consequentemente, tirar o negro de sua posição subordinada seria jogar em suas costas uma responsabilidade com a qual não seria

13 "Trained from the cradle up to think and feel that their masters were superior, and invested with a sort of sacredness, there were few who could rise above the control which that sentiment exercised" (DOUGLASS, 1881, p. 142). 
apto a lidar. Consequentemente, tal qual uma criança, o negro não estaria pronto para gozar plenamente de sua liberdade. De repente, a escravidão cria a imagem para si de uma instituição benevolente e patriarcal, onde o negro é feliz em sua submissão. Escravizá-lo significava protegê-lo de si mesmo (NICHOLS, Jr. 1949, p. 202).

Os abolicionistas como Douglass conheciam bem esse e outros argumentos próescravistas, tendo de dedicar trechos extensos a sua refutação. No século XIX, o mundo natural era o grande referencial de justificativas ideológicas; ele servia como uma tela contra a qual um ou outro grupo podia projetar praticamente o que bem entendesse. Sobretudo em um país "cuja riqueza e autoimagem, desde o início, residia tão pesadamente nas benções da natureza, a disputa terminológica e política acerca de o que é 'natural' foi particularmente acirrada". 14

Dentro da estrutura narrativa de escravos, o papel da reflexão não serve meramente à construção de uma personagem mais complexa, com mais camadas de significado. Ela é resultado do embate entre dois momentos da subjetividade, a do escritor em 1845, aos vinte e seis anos, encenando o Douglass adolescente. Enquanto a versão jovem de sua persona fala para dentro, esgotando sua mensagem de liberdade em objetos inanimados, a versão mais velha, munida de pena e tinta, publica uma das grandes armas contra o sistema escravista. A função da reflexão nas narrativas de escravos é a de fornecer uma interpretação postecipada do significado de um ou outro evento na vida da personagem, tendo sempre em vista seu papel na conquista da liberdade. Ao contrário do que se passa num texto romântico, o papel da divagação tem um fim paradoxalmente concreto, calcado na realidade bruta das coisas: ela crê na ideia da transformação direta do mundo por meio da denúncia.

De um ponto de visto do conteúdo, há um curioso paralelo entre a expressão literária de escravos norte-americanos com a de judeus da diáspora do século $\mathrm{XX}$ : todas as características descritas acima, e que distinguem as letras afro-americana da anglo-saxã no período antebellum, são também características da Trümmerliteratur de judeus sobreviventes ao Holocausto. ${ }^{15}$ Ambas são literaturas de denúncia; eventos recorrentes nelas são a fome, o desamparo e a desumanização de indivíduos capazes de racionalizar a perda do estatuto que os separa de coisas - não por acaso, duas das palavras mais recorrentes na literatura dos

14 "[...] whose wealth and self-image from the start rested so heavily upon the blessings of nature, the ${ }_{15}$ terminological and political contest over what is 'natural' has been especially fierce” (FINSETH, 2001, p. 343).

${ }^{15}$ Ver um breve, mas brilhante, resumo da literatura testemunhal em questão em Young, 1997, p. 27-28. 


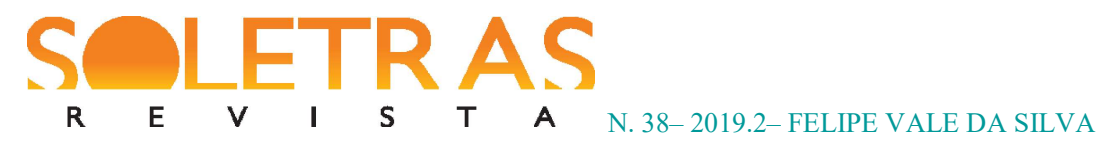

negros da época são brute e beast. O homem se transforma em besta de carga. A escravidão, por mais economicamente promissora tenha sido para o mundo colonial, é motor de animalização, do oposto do avanço civilizatório ao qual o capitalismo industrial (no caso dos EUA) e o imperialismo alemão (no contexto do Holocausto) supostamente serviam.

De certa forma, o surgimento (e estudo) de novas literaturas diaspóricas do século XX contribuíram para uma nova apreciação da primeira literatura afro-americana. ${ }^{16}$ A partir de 1980, F. O. Matthiessen tornou-se alvo de correções por parte de feministas, ativistas negros, latino-americanose de demais minorias. Foi nessa época que surgiram obras contestatórias como Beneath the American Renaissance de DavidReynold (1988) e The American Renaissance Reconsidered de Walter Benn Michaels e Donald E. Pease (1989). Seu cânone representativo passou a ser sentido como restrito demais, injusto com a diversidade expressiva da literatura oitocentista, como mostramos no caso de Douglass.

No entanto, a importância de Matthiessen não deve ser negligenciada; ele foi um grande popularizador da cultura do século XIX, restaurando a apreciação do público leitor por muitos autores então esquecidos (como Melville), e junto de outros estudiosos, ajudou a firmar um currículo universitário de forma quea área de American Studies fosse devidamente reconhecida tal qual uma disciplina acadêmica. Mas daí deriva o fato de que essa disciplina teve um início deficitário; sua ênfase era exclusiva a uma parcela pequena de autores e obras produzidas naquele país. Metodologicamente, ela se desenvolveu a passos cambaleantes, guiando-se por uma teoria e práxis inconsistentes.

Mas um dado sobre essa primeira aceitação das narrativas de escravos no cânone é digno de lembrança: conforme mencionamos acima como parte do trabalho (e inovação) de Douglass foi escrever textos capazes de refutar as grandes ideologias da época: o racismo e nativismo anglo-saxão, utilizando-se da maestria retórica que lhe é característica. É uma ironia que, para ganhar papel no cânone da literatura anglo-saxã, Douglass tenha tido que passar por um novo teste na primeira metade do século XX, dessa vez de ordem estética. Algumas décadas mais tarde, na época de crescente interesse acadêmico em análises desconstrutivistas, o foco se tornou outro: repensar quão autênticas e historicamente relevantes tais narrativas de fato eram.

\footnotetext{
${ }^{16}$ Ver, sobretudo, o estudo de James E. Young (1997). Para uma aproximação de Young e narrativas de escravos, ver DeLombard, 2007, p. 136.
} 


\section{Segunda crítica — a tese da falsificação (Sekora) e o caso Venture Smith}

A segunda crítica ao consórcio entre abolicionistas brancos / autores negros vem do outro lado do espectro. Um grande apreciador da cultura afro-americana, John Sekora (1987), questiona se a interferência de abolicionistas brancos não contribuiu para uma falsificação da verdadeira mensagem dos escravos. Em suas palavras, caso tal suposição seja correta, as narrativas deveriam ser encaradas com reserva, como documentos híbridos da experiência histórica norte-americana: sua mensagem é negra, mas seu invólucro é branco. ${ }^{17}$

Muitas objeções a tal ideia surgiram nos últimos anos. Levine (2007, p. 100) e Gould (2007, p. 24), por exemplo, criticam o purismo em querermos exigir uma expressão imaculadamente negra.Fenômenos literários, sobretudo em um país miscigenado como os Estados Unidos, não surgem e permanecem isolados em guetos.

Em partes, o triunfo da literatura produzida por escravos se deveu ao fato de ela ter entrado nas casas de americanos brancos, outrora descrentes do potencial intelectual dos negros. Em 1829, foi David Walker quem prescreveu a fórmula mais eficaz para destruir a ilusão da supremacia branca: negros deveriam se educar fora do sistema e escrever seus próprios livros, provando, por meio deles, sua capacidade intelectual; era redundante esperar benevolência do público anglo-saxão. O grande fato a respeito da democracia estadunidense, afirma Walker, é que "julgamos os homens por suas obras". ${ }^{18} \mathrm{Na}$ altura de 1840 , narrativas de escravos já haviam se tornado uma forma extremamente popular de literatura nos EUA, Inglaterra, Holanda e Alemanha. ${ }^{19}$ Seus autores haviam passado o teste de Walker, digamos, iniciando um estágio no debate público onde finalmente assumiam uma posição de igualdade frente aos escravagistas. Mesmo que essa não fosse sua posição na sociedade civil.

No entanto, a relutância de Sekora é justificável. Ela contribuiu para a afroamericanística uma vez que nos condicionou a lembrar o hibridismo como característica central das narrativas de escravos. Este, antes de ser um traço negativo, permeia o fenômeno de certo caráter coletivista, responsável por inaugurar um novo momento na literatura daquele país. A ânsia por publicar narrativas de escravos nos rendeu "um dos mais extensos corpora

\footnotetext{
${ }^{17}$ Remeto aqui ao título genial de seu artigo de 1987, Black message/White envelope.

18 "[...] we judge men by their works" (WALKER, 1830, p. 20).

${ }^{19}$ Sobre tiragens das principais narrativas e sua difusão, ver Davis \& Gates Jr., 1985, p. xv-xvi, xxxi.
} 
de literatura produzido por qualquer grupo de escravos na história" mundial. ${ }^{20}$ Hoje, ela conta como o principal repertório documental a vida do Sul dos Estados Unidos antes da Guerra Civil, fornecendo detalhes sobre o cotidiano das pessoas comuns que a historiografia da época — obcecada por grandes homens/grandes eventos — acabou negligenciando (cf. DAVIS \& GATESJR., 1985, p. xiv).

No entanto, o gênero não iniciou como órgão de defesa da abolição. Sua história é mais idiossincrática do que Sekora assume. Pensemos no exemplo de A Narrative of the Life and Adventures of Venture, a Native of Africa (1798), texto autobiográfico de um africano livre. A breve narrativa tem o alvo explícito de contar uma história que exibao caráter de "honestidade, prudência e industriosidade" de seu autor. ${ }^{21}$ Este, de nome Venture Smith, age sob os imperativos da respeitabilidade vitoriana, às obrigações de um homem adulto perante sua família e estabilidade financeira. De fato, Venture tem um "foco econômico, quase exclusivo na capacidade de um escravo comprar sua própria liberdade". ${ }^{22}$ Em seu livro fala-se sobre dinheiro a todo momento, a ponto de ele reproduzir os mesmos valores que críticos da escravidão (e do capitalismo industrial, mais tarde) viram como problemáticos: Smith constantemente nos lembra que tudo e todos têm um preço na sociedade americana. Consequentemente, o homem negro que quiser se adaptar a tal mundo teria de saber como jogar o jogo, digamos, do homem branco. Aqui, a transformação bem-sucedida num ianque respeitável reflete-se em sua linguagem literária. Ao relatar a longa doença sofrida pelo filho, que culminou em sua morte, ele conclui: "Em meu filho, além da perda da vida, perdi o equivalente a setenta e cinco libras". ${ }^{23}$ Mais para frente, sobre a convalescença da filha, "as contas para o médico cuidar dela durante sua doença assomou quarenta libras". ${ }^{24}$ Em suma, a construção da identidade livre obedece a constante daquele final de século XVIII, em que liberdade era igualada à posse de propriedades (cf. GOULD, 2007, p. 90).

E o caso não para por aí. Essa é uma história de libertação onde, uma vez instalado como homem livre no Norte, Smith adquire seus próprios escravos. "Após [comprar a liberdade de] minha esposa, comprei um homem negro por quatrocentos dólares. Mas já que

\footnotetext{
20 "[...] one of the largest bodies of literature produced by any group of slaves in history" (DAVIS \& GATES Jr., 1985, p. xii).

21 “[...] honesty, prudence and industry”" (SMITH, 1798, p. iv). Ver comentários em Levine, 2007, p. 103.

22 "[...] an almost exclusively economic focus on the slave's capacity to buy his own freedom" (GOULD, 2007, p. 14).

23 "In my son, besides the loss of his life, I lost equal to seventy-five pounds" (SMITH, 1798, p. 26).

24 “The physician's bills for attending her during her illness amounted to 40 pounds" (SMITH, 1798, p. 28).
} 
ele tinha inclinação a voltar para seu antigo mestre, deixei-o ir", lemos no terceiro quarto da narrativa. ${ }^{25} \mathrm{O}$ narrador constantemente nos lembra ter sido um bom mestre, alforriando seus negros quando lhe parecia adequado. Para o movimento abolicionista posterior, tal abordagem era estrategicamente desastrosa. Smith encara escravidão como um fato da vida, enquanto o abolicionismo, como uma aberração humanitária; uma vez que sempre vão existir mestres e servos, aquele postula, que ao menos meu exemplo seja o de um bom mestre. Tal seria a postura digna de um self-made man negro. O livro conclui com um documento, um certificate (algo como uma carta de recomendação assinada por autoridades civis), prática que se tornou bastante comum mais para frente. "VENTURE sustentou o caráter de um servo fiel, e aquele de um homem moderado, honesto e industrioso" (SMITH, 1798, p. 32); é essa a imagem final daquele homem.

O autor, de fato, "detesta ser um escravo, mas em sua mente a transgressão intencional é muito pior do que o cativeiro obrigatório". ${ }^{26}$ Todavia, o mal moral executado pelo indivíduo singular é pior que uma má legislação. Falta-lhe uma compreensão o peso das instituições na vida de uma coletividade, como formadora de atitudes pessoais.

Escritores posteriores apresentarão uma atitude menos apologética perante a escravidão; no século XIX, ela já aparece em suas narrativas como um crime contra a humanidade, que precisa ser confrontado radicalmente. Para isso valia expor nominalmente proprietários de escravos, mestres cruéis e caçadores de recompensas (GOULD, 2007, p. 18). Só aí surge na literatura afro-americana a retórica dos fatos da qual fala Edward P. Young (1997, p. 26), e ela surge numa época que entendeu que a História nunca se desdobra independentemente da forma como a representamos (1997, p. 20). A escravidão jamais seria entendida intuitivamente por norte-americanos como a aberração humanitária que é; era preciso esmiuçá-la em todas suas dimensões, comprovar seus fatos mediante documentação, colocar o escravo na posição de porta-voz.

O momento de virada na história das narrativas de escravos ocorreu em 1838. Um exescravo do Alabama chamado James Williams foi o primeiro a ter sua narrativa editada e publicada por uma organização abolicionista, a American Anti-Slavery Society. Seguindo um momento de radicalização do movimento, o texto de James Williams cria modelo de

\footnotetext{
25 "Next after my wife, I purchased a negro man for four hundred dollars. But he[,] having an inclination to return to his old master, I therefore let him go" (SMITH, 1798, p. 27).

26 "He detests being a slave, but in his mind willful wrongdoing is far worse than enforced captivity" (PIERCE, 2007, p. 88).
} 
organização textual muito diverso do precedente, e que parece se adequar melhor ao que Sekora, em seu ensaio, considera uma narrativa de escravos por excelência.

O texto inicia com um longo prefácio não assinado, introduzindo não o indivíduo James Williams, mas o tema da escravidão: “'A escravidão americana,' disse o célebre John Wesley,' é a mais vilda face da Terra! ${ }^{, 27}$ Os prefaciadores elegem um nome célebre Wesley, o famoso abolicionista do século XVIII — para então desmantelarem o argumento de que a escravidão é algo natural nas sociedades humanas. Aquilo era como dizer: nós, abolicionistas, temos uma tradição antiga, com nossos próprios intelectuais e armas para lutar contra o sistema escravagista. Tal sistema não só é antinatural, como deve ser analisado em contexto: e a escravidão nos Estados Unidos da América consegue superar todas as anteriores em seus efeitos sociais devastadores (WILLIAMS, 1838, p. iii-v). Em seguida, discorre-se um longo argumento teológico a favor da manumissão. Seguindo a ideologia do Destino Manifesto, os prefaciadores afirmam que só uma América sem escravos, com imigrantes europeus e africanos trabalhando juntos, poder-se-á construir um futuro promissor. Até isso ocorrer, as bênçãos divinas lhe estavam vetadas.

A escravidão "assume o direito de transformar criaturas morais em brutos; [...] legaliza a usurpação humana da autoridade Divina” (WILLIAMS, 1838, p. v-vi). Como voltará a acontecer em tantos outros textos, o argumento teológico se mistura a questões de organização social. A crença por trás dessa prática é a de que os Estados Unidos são um país vivendo de acordo com preceitos cristãos, e a escravidão é corpo estranho em sua sociedade. Muitos escravagistas defendiam a ideia diametralmente oposta: escravidão seria parte integrante do plano divino, atuando como reguladora da relação entre grupos humanos. Mais especificamente, ela seria a dádiva encontrada por anglo-saxões, o povo escolhido, para construírem sua economia no terreno selvagem do Novo Mundo, permitindo-lhes a competir com grandes potências europeias. No restante do prefácio, este grupo de defensores da prática se torna alvo; aqui o debate pelo fim da escravatura assume contornos semelhantes do que teriam em uma corte.

Lemos menções à legislação, casos legais, notícias de jornais, e até mesmo explicação de detalhes etnográficos sobre o mundo habitado por mestres, capatazes e servos que, para um

27 “'American Slavery,' said the celebrated John Wesley,' is the vilest beneath the sun!' (WILLIAMS, 1838, p. iii; grifo do autor). 
morador da Nova Inglaterra, talvez fossem desconhecidos. ${ }^{28}$ Essa mistura de registros discursivos, com constantes excursos contendo curiosidades sobre a vida desconhecida daquela parcela da população, servia a objetivos pontuais. Tratava-se de uma mistura de vozes brancas e negras, decerto, mas que se provou bem-sucedida no contexto em que mesmo um negro alforriado não tinha direito à representação jurídica. A rigor, o afro-americano, às vésperas da Guerra Civil, não gozava de cidadania plena. Precisamente por não ter participação no fórum civil, ele a conquistou no fórum público dos discursos literários, na esfera pública. Antes de ser uma falsificação da verdadeira mensagem, como supôs Sekora, esta manobra permitiu que sua mensagem chegasse a nós (DeLOMBARD, 2014, p. 77).

Autores pró-escravidão responderam à narrativa de James Williams de diversas formas. A reação imediata foi descreditar sua autenticidade (BRUCE Jr. 2007, p. 34), parcial ou completamente, retratando, em seus próprios livros, o abolicionista branco do Norte como um oportunista, disposto a falsificar a realidade supostamente idílica das lavouras do Sul. Aquela era uma guerra econômica, além de um embate de ideias: o que lemos nas confederate ou plantation novels, romances escritos para elogiar a instituição peculiar do Sul, é "um retrato nostálgico da lavoura sulista, uma concepção tardia de mundo que, na verdade, dificilmente [poderia ter existido]". ${ }^{29}$ Nelas, a vilificação do negro como indivíduo desordeiro, incapaz de controlar a si próprio, é acompanhada pela crítica constante ao Norte dos EUA. Se o Sul agrário tinha suas lavouras e pelourinhos, no Norte, trabalhadores brancos sofriam a exploração da economia industrial pela mão de grandes capitalistas. Nortistas, por fim, eram grandes hipócritas ao ignorar a opressão do próprio homem branco. Tal crítica só se sustentaria mediante ocultação de algumas verdades inconvenientes sobre a vida sulista, é evidente, ${ }^{30}$ mas forçou editores abolicionistas a autenticarem seus livros com um rigor

\footnotetext{
${ }^{28}$ No texto de James Williams há exemplos da criação de sabujos treinados desde filhotes para recapturar escravos fugidos (1838, p. 15); das condições de moradia dos cativos (ibidem, p. 45-46); da religiosidade em seu meio (1838, p. 73-74).

29 "[...] a nostalgic portrayal of the plantation South, a latter-day conception of a world which, in fact, [could] hardly [have] existed at all" (NICHOLS Jr., 1949, p. 201).

${ }^{30}$ A começar pelo fato de que também os pobres do Sul eram vítimas de monopólios agrários muito parecidos com os monopólios industriais do Norte. Blassingame (1975b, p. 329) resume bem como a escravidão era positiva somente para uns poucos proprietários de terra, mas "pouco lucrativa para a região [em si; ela] acentuava divisões de classes com grandes proprietários dominando a sociedade, impedia o desenvolvimento de uma vida familiar normal entre negros, tornava o trabalho manual indigno, afetava a moral, caráter e personalidade dos brancos adversamente, e causou a Guerra Civil”.
} 
inexistente à época mesmo em livros de historiografia. ${ }^{31}$ Caso contrário, tudo o que produzissem seria tachado como enviesado.

A partir de James Williams, esses livros passaram a dedicar longos trechos a relatos da violência cotidiana, das pequenas privações e terror psicológico criado por capatazes, mestres e senhores a fim de garantir a submissão de seus servos (GOULD, 2007, p. 19). Aqui volta o caráter 'pouco artístico', demasiado preso à banalidade do dia a dia, que literatos neorromânticos criticaram na prosa afro-americana.

\section{Defesa - a tese do formato definitivo (Olney)}

Por função do ceticismo de ambos os lados da crítica, narrativas de escravos foram compreendidas até meados de 1980 como um gênero simples, naïfe estruturalmente pobre. Assumia-se que todas tratam da mesma coisa, de forma que, se lemos uma, já teríamos lido todas (OLNEY, 1984, p. 46). Isso ocorreu até um grande estudioso do gênero autobiográfico, James Olney, escrever um artigo expondo o descabimento dessa proposição. Trata-se de "I Was Born": Slave Narratives, Their Status as Autobiography and as Literature, de 1984.

Por meio de análise estrutural de dezenas de obras, Olney nos legou um ensinamento duplo: em primeiro lugar, narrativas de escravos se distanciam do modelo clássico de autobiografias. Na realidade, elas o inovam. Mais do que funcionar como um ato de memória, em que o indivíduo maduro reflete os caminhos que o levaram a ser a pessoa singular que é, narrativas de escravos representam os desafios de uma coletividade, discutem legislação escravista e eventos históricos, além de, como vimos, disporem de um repertório de ensinamentos etnográficos inexistente nas belas letras até então. Seu tema não era um indivíduo que foi capaz de alcançar sua autonomia, portanto, mas um indivíduo que ainda não existia, o negro livre e gozando plenamente do estatuto do cidadão. Ela olha para fora e para o futuro, não para a história íntima passada.

Em segundo lugar, a estrutura das narrativas de escravos é singular nas letras norteamericanas. Resumamos abaixo os principais elementos narrativos identificados por Olney(1984, p. 50-51). Via de regra, elas possuem:

\footnotetext{
${ }^{31}$ Sobre a dinâmica de autenticação, ver o ensaio brilhante de Blassingame (1975a, p. 474 et seq). 


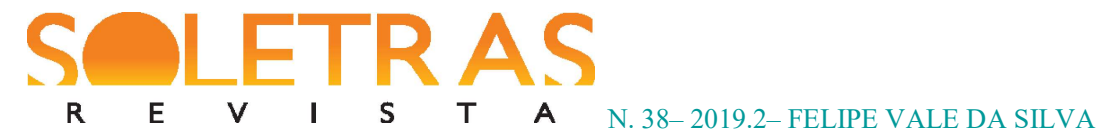

A. Um retrato do sujeito da narrativa, devidamente assinado;

B. A folha de rosto com um título "Narrativa de X, escrita por ele (a) mesmo(a)";

C. Testemunhos de abolicionistas brancos de renome, que funcionam como cartas de recomendação do caráter do sujeito retratado. Muitas vezes, nessa seção inicial do texto, constam considerações acerca do estilo simples, pouco ornamentado do texto, justificado por seu interesse de servir como documento contra a escravidão;

[...]E. A narrativa propriamente dita. Esta, por sua vez, embora não siga um padrão argumentativo, cobre uma série de temas de interesse para a luta abolicionista no período antebellum, tais quais:

1. A sentença de abertura "Eu nasci escravo(a)", seguido de detalhes sobre o local de nascimento, o pouco conhecimento do sujeito a respeito de suas origens e data de nascimento;

[...] 3. Descrição de um mestre, senhora ou capataz cruel; detalhes sobre torturas físicas e psicológicas inferidas aos escravos e, geralmente, um caso de resistência à violência institucionalizada;

8. Um relato de um leilão de escravos, ao qual se seguem reflexões sobre separações das famílias negras e consequências traumáticas do evento;

[...] 10. Descrição de tentativas bem-sucedidas de fuga da escravidão, geralmente contendo perseguidores munidos de cães de caça, quacres bem-intencionados que abrigam fugitivos em seus lares, além de reflexões sobre o processo de adaptação do negro em algum estado livre da federação ou no Canadá.

Como se pode ver na numeração dos tópicos, esses são apenas alguns dos elementos formadores dessa tradição literária. Tais convenções já se haviam cristalizado em meados de 1820 , e voltaram a ser reproduzidas por mais duas gerações de afro-americanos pelo simples fato de terem se provado efetivas na luta abolicionista.

O que o autor deixou de abordar, no entanto, é como esse processo se deu. É ponto comum dizer que, em qualquer tradição literária duradora, estruturas narrativas nunca se estabelecem de imediato, como se fossem decididas por um punhado de grandes escritores numa sala de reuniões. Sobretudo no caso das narrativas de escravos, o 'formato definitivo' 
do qual fala Olney, produzido entre 1845 e 1861, resultou de décadas de experimentos entre autores, editores e público. Muitos desses experimentos surgiram num contexto histórico em que tal identidade literária não existia — como vimos no caso de Venture Smith —, foram lidos e julgados por uma comunidade de futuros produtores de cultura. Seus elementos mais relevantes para a causa abolicionista passaram a ser repetidos de forma que hoje reconhecemos algumas dezenas de textos como parte da mesma vertente literária: as narrativas de escravos.

A tarefa atual de nossos estudos é a de ir além da tese da 'forma definitiva' de Olney, pensando o gênero diacronicamente, explicando quando $X$ e $Y$ elementos se consolidaram na produção das narrativas. Hoje temos dados historiográficos suficientes para tal. A exemplo do diagrama de Olney, é possível afirmar que a característica B das narrativas — o fato de elas se chamarem, via de regra, Narrativa de X, escrita por ele(a) mesmo(a) - surge em 1825 com o livro de William Grimes, um comerciante ambulante estabelecido em New Haven, Connecticut. $^{32}$ Este livro não foi apoiado por qualquer associação antiescravista; Grimescobriu os custos de uma tiragem modesta, e, por esse motivo, foi redescoberto há tão pouco tempo. A distribuição de seu livro ficou restrita à sua cidade, a um grupo de amigos. Escritores posteriores aprenderam a sobreviver ao mercado editorial, valendo-se de técnicas apelativas e propaganda desconhecidas por Grimes.

Esse é um exemplo de vários. Tal pesquisa é promissora uma vez que logre refutar as duas teses elencadas neste artigo: (1) ela prova, contra Matthiessen, que narrativas de escravos formam uma tradição literária singular, de grande impacto na história do pensamento norteamericano, e que (2)antes de um gênero imposto pelos abolicionistas brancos como assumiu Sekora, este foi formado por décadas de escrita negra independente, lido e repensado por uma comunidade de leitores interessados numa nova forma de expressão atenta às urgências da comunidade afro-americana.

Por fim, retraçar os caminhos e descaminhos desses textos pioneiros nos permite vislumbrar uma série de tensões sociais que impulsionaram uma nova estética de combate no século XIX, em plena era romântica. Ao estudá-la, temos acesso às origens institucionais da primeira tendência literária originalmente americana, que definiu a produção da prosa afroamericana posterior.

\footnotetext{
${ }^{32}$ A edição aqui consultada foi a segunda, de trinta anos mais tarde. Ver Grimes, 1855. 


\section{Referências}

BLASSINGAME, John W. Using testimony of ex-slaves: approaches and problems. The Journal of Southern History, 1975a, vol. 41, no. 4, p. 473-492.

. The Planter on the Couch: Earl Thorpe and the Psychodynamics of Slavery. The Journal of Negro History, 1975b, vol. 60, no. 2, p. 320-331.

BRUCE JR., Dickson D. Politics and political philosophy in the slave narrative. In: FISCH, Audrey A. (Ed.) The Cambridge Companion to the African American Slave Narrative. Cambridge: Cambridge University Press, 2007, p. 28-43.

DAVIS, Charles T.; GATES JR., Henry Louis. The Slave's Narrative. New York: Oxford University Press, 1985.

DeLOMBARD, Jeannine Marie. Slavery on Trial: Law, Abolitionism, and Print Culture. Chapel Hill: The University of North Carolina Press, 2007.

DOUGLASS, Frederick. A Narrativa da Vida de Frederick Douglass, um Escravo Americano. Escrita por ele mesmo. Tradução de Leonardo Poglia Vidal. São Paulo: Aetia Editorial, 2018.

. Life and Times of Frederick Douglass, written by himself. Hartford: Park Publishing, 1881.

. Narrative of the Life of Frederick Douglass, an American Slave. Written by himself. Boston: Published at the Anti-Slavery Office, 1845.

FINSETH, Ian. David Walker, Nature's Nation, and Early African American Separatism. Mississippi Quarterly, 2001, vol. 54, no. 3, p. 337-362.

GOULD, Philip. The rise, development, and circulation of the slave narrative. In: FISCH, Audrey A. (Ed.) The Cambridge Companion to the African American Slave Narrative. Cambridge: Cambridge University Press, 2007, p. 11-27.

GRIMES, William. Life of William Grimes, the Runaway Slave, Brought Down to the Present Time. New Haven: s/e, 1855. 
JOHNSON, Charles. Foreword. In: TAYLOR, Yuval (Ed.). I was Born a Slave: an Anthology of Classic Slave Narratives. Chicago: Lawrence Hill Books, 1999.

LEVINE, Robert $\mathrm{S}$. The slave narrative and the revolutionary tradition of American autobiography. In: FISCH, Audrey A. (Ed.) The Cambridge Companion to the African American Slave Narrative. Cambridge: Cambridge University Press, 2007, p. 99-114.

MATTHIESSEN, F. O. American Renaissance. Art and Expression in the Age of Emerson and Whitman. New York: Oxford University Press, 1949.

MORRISON, Toni. Unspeakable Things Unspoken: the Afro-American Presence in American Literature. Michigan quarterly review, 1989, vol. 28, No. 1, p. 1-34.

NICHOLS JR., Charles H. Notes and Documents. The Case of William Grimes, the Runaway Slave. William and Mary Quarterly, $3^{\text {rd }}, 1951$, vol. 8, no. 4, p. 552-560.

OLNEY, James. "I Was Born": Slave Narratives, Their Status as Autobiography and as Literature. Callaloo, 1984, no. 20, p. 46-73.

PARKER, Theodore. Position and Duties of the American Scholar. In: The Collected Works of Theodore Parker. Vol. VIII. London: Trübner \& Co., 1864, p. 217-256.

REID-PHARR, Robert F. The slave narrative and early Black American literature. In: FISCH, Audrey A. (Ed.) The Cambridge Companion to the African American Slave Narrative. Cambridge: Cambridge University Press, 2007, p. 137-149.

SEKORA, John. Black Message/White Envelope: Genre, Authenticity, and Authority in the Antebellum Slave Narrative. Callaloo, 1987, no. 32, p. 482-515.

SILVA, Felipe Vale da. A literatura alemã de Wolfgang Menzel, resenhada por Heinrich Heine: tradução comentada. Revista Belas Infiéis, 2017, vol. 2, no. 6, p. 177-197.

SMITH, Venture. A Narrative of the Life and Adventures of Venture, a Native of Africa: But Resident above Sixty Years in the United States of America. Related by Himself. New London, CT: C. Holt, 1798. 
WALKER, David. Walker's Appeal, in four articles. Third Edition. Boston: s/e, 1830. Disponível em: https://docsouth.unc.edu/nc/walker/walker.html. Acesso em: 31/ago/2018.

WILLIAMS, James. Narratives of James Williams, an American Slave, who was for several years a driver on a cotton plantation in Alabama. New York: The American Anti-Slavery Society, 1838.

YOUNG, James E. Beschreiben des Holocaust: Darstellung und Folgen der Interpretation. Stuttgart: Suhrkamp Verlag, 1997.

\title{
The exceptional genre: observations on the reception of slave narratives in the USA
}

\begin{abstract}
This paper deals with a twofold story of resistance: firstly, with the story of slave narratives as tools against the US slave system and, on the other hand, with the story of resistance of the literary establishment against the assimilation of the genre by the canon. Three arguments are hereby analyzed, all related with the reception of this first moment of African-American prose in the $20^{\text {th }}$ century. Such an exercise allows one to verify how many of the genre's structural elements could only be gradually assimilated as interdisciplinary approaches accumulated and, thus, provided ground to a community of readers capable of appreciating them as a singular genre in the US history. For each argument against the appreciation of slave narratives an exceptional literary example will be contrasted with: firstly, New Criticism's and F. O. Matthiessen literary approaches will be contrasted with a rhetorical analysis on Frederick Douglass' work; in a second stance, John Sekora's argument against the hybrid form of slave narratives will be juxtaposed to Olney's structuralist perspective; at this point, narratives by Venture Smith, James Williams and William Grimes will be taken in account.
\end{abstract}

Keywords: Slave narratives. African-American Literature. Frederick Douglass. Reception History. Abolitionism.

Recebido em: 19 de setembro de 2018.

Aceito em: 29 de janeiro de 2019. 